\title{
Validitas Pemeriksaan Ankle Reflex untuk Deteksi Diabetic Peripheral Neuropathy pada Pasien Diabetes Melitus Tipe 2
}

\author{
Ankle Reflex Examination Validity as Diabetic Peripheral Neuropathy Detection on Patient of \\ Diabetes Mellitus Type 2
}

\author{
Wizard Eka Putra Azaka ${ }^{1 *}$, Agus Yuwono ${ }^{2}$, Erida Wydiamala ${ }^{3}$ \\ ${ }_{1}$ Program Studi Pendidikan Dokter, Fakultas Kedokteran, Universitas Lambung Mangkurat, Banjarmasin \\ ${ }^{2}$ Bagian IImu Penyakit Dalam, Fakultas Kedokteran, Universitas Lambung Mangkurat, Banjarmasin \\ ${ }^{3}$ Bagian Parasitologi, Fakultas Kedokteran, Universitas Lambung Mangkurat, Banjarmasin
}

DATA OF ARTICLE:

Received: 18 Sep 2017

Reviewed: 25 Jan 2018

Revised: 1 Jul 2018

Accepted: 25 Sep 2018

*CORRESPONDENCE:

wizard.azaka5@gmail.com

DOI:

10.18196/mm.190124

TYPE OF ARTICLE:

Research
Abstrak: Diabetic Peripheral Neuropathy (DPN) adalah bentuk komplikasi yang paling banyak pada pasien diabetes. Ankle Reflex (AR) merupakan pemeriksaan fisik sederhana yang dapat digunakan sebagai prosedur deteksi untuk mencegah morbiditas dan mortalitas yang disebabkan oleh DPN dengan mengevaluasi fungsi saraf sensoris dan motoris. Tujuan penelitian ini adalah untuk mengetahui validitas AR sebagai prosedur deteksi DPN pada pasien diabetes melitus (DM) tipe 2. Penelitian dilakukan di RSUD Dr. H. Moch. Ansari Saleh Banjarmasin. Jenis penelitian ini adalah uji diagnostik dengan pendekatan cross-sectional. Penelitian melibatkan 69 pasien DM tipe 2 di Poliklinik Penyakit Dalam sebagai peserta. Pasien dievaluasi menggunakan skor Diabetic Neuropathy Examination (DNE), Diabetic Neuropathy Symptom (DNS) dan pemeriksaan AR. Data dianalisis menggunakan tabel uji diagnostik 2x2 dan kurva receiving operating characterictic (ROC). Hasil menunjukkan bahwa AR memiliki nilai sensitivitas $100 \%$, spesifisitas $72,73 \%$, akurasi $82,61 \%$, nilai duga positif $67,57 \%$, nilai duga negatif $100 \%$ dan 0.88 area under curve (AUC). Simpulan penelitian ini adalah AR memiliki nilai validitas yang baik dan dapat digunakan sebagai prosedur deteksi DPN yang cepat dan mudah untuk pasien DM tipe 2.

Kata Kunci: Validitas; Ankle Reflex; Diabetic Peripheral Neuropathy; Diabetes Melitus Tipe 2

\footnotetext{
Abstract: Diabetic peripheral neuropathy (DPN) is the most common and troublesome complication which affect diabetic patients. Ankle Reflex (AR) is a simple physical examination which can be used as detection procedure to prevent morbidity and mortality caused by DPN by evaluating both motor and sensory nerves function. This study aimed to discover ankle reflex validity as DPN detection procedure on type 2 diabetes mellitus (DM) patients at RSUD Dr. H. Moch. Ansari Saleh Banjarmasin. This was a diagnostic test study with cross-sectional design. Subjects were 69 type 2 DM patients at internal medicine clinic. Patients were evaluated by using diabetic neuropathy examination (DNE) score, diabetic neuropathy symptom (DNS) score and AR examination. Data was analyzed by using $2 \times 2$ diagnostic test table and receiving operating characteristic (ROC) curve. The result shows that AR had 100\% sensitivity, 72,73\% specificity, 82,61\% accuracy, 67,57\% positive predictive value, $100 \%$ negative predictive value and 0,88 area under curve (AUC). In conclusion, AR has good validity value and can be used as rapid and simple DPN detection procedure on type 2 DM patients.
} 
Keywords: Validity; Ankle Reflex; Diabetic Peripheral Neuropathy; Type 2 Diabetes Mellitus

\section{PENDAHULUAN}

Diabetic Peripheral Neuropathy (DPN) merupakan komplikasi yang paling sering terjadi pada pasien Diabetes Melitus (DM) dan bertanggung jawab terhadap $50-75 \%$ amputasi non traumatik pada pasien DM. Berdasarkan Infodatin tahun 2014, angka prevalensi DPN di RSUPN Dr. Cipto Mangunkusumo Jakarta sebesar $54 \%$ dari semua komplikasi DM yang didata. ${ }^{1}$

Patogenesis terjadinya DPN masih belum diketahui secara pasti, namun melibatkan beberapa proses yaitu adanya kerusakan endotel pembuluh darah, aktivasi jalur poliol, Advanced Glycation End Products (AGEs) dan aktivasi jalur Protein Kinase $C$ (PKC). ${ }^{2,3}$ Kerusakan saraf yang terjadi pada DPN dapat bergejala nyeri, sensasi seperti tertusuk, terbakar di malam hari yang melibatkan kerusakan serabut saraf berdiameter kecil atau justru hilangnya refleks miotatik, sensasi getar, raba halus yang simetris berjalan dari distal ke proksimal dan bergantung pada panjang neuron (lebih utama di kaki) yang melibatkan kerusakan serabut saraf berdiameter besar khususnya serabut saraf sensoris jenis Aa. 4,5

Hal yang perlu diperhatikan dari DPN adalah terbentuknya ulkus yang tidak disadari oleh pasien yang meningkatkan risiko infeksi bahkan amputasi terutama di ekstremitas bawah. Oleh karena itu, perlu dilakukan deteksi pada DPN agar pasien mengetahui kondisi yang dialaminya sehingga dapat mencegah kerusakan yang lebih parah melalui upaya-upaya perawatan dan pengobatan. Menurut konsensus San Antonio, tidak ada pemeriksaan baku emas yang ditetapkan namun direkomendasikan setidaknya melakukan satu dari lima metode, yaitu sistem penilaian skor gejala, sistem penilaian skor pemeriksaan fisik, Quantitive Sensory Testing (QST), tes fungsi otonom kardiovaskuler dan elektrodiagnosis. ${ }^{6}$

Terdapat pemeriksaan fisik yang mudah dilakukan untuk mendiagnosis DPN yaitu Ankle Reflex (AR). Ankle reflex dapat menurun bahkan hilang di awal terjadinya DPN. Hal ini dikarenakan kerusakan serabut saraf sensoris jenis Aa yang merupakan serabut sensoris pada kumparan otot. Reseptor kumparan otot rangka dapat dirangsang melalui ketukan pada tendon dan kemudian impuls akan dilanjutkan menuju ganglion dorsalis medula spinalis dan bersinaps dengan neuron eksitatorik yang akan melanjutkan impuls menuju neuron motorik sampai pada otot rangka. Kerusakan neuron pada tahap lebih lanjut akan merusak neuron motorik, namun keru- sakan serabut saraf sensoris lebih dulu terjadi sehingga dapat dideteksi sebelum DPN semakin parah. ${ }^{5}$

Tujuan penelitian ini adalah untuk mengetahui validitas AR sebagai prosedur deteksi DPN pada pasien DM tipe 2 di RSUD di RSUD Dr. H. Moch. Ansari Saleh Banjarmasin

\section{BAHAN DAN CARA}

Penelitian ini adalah penelitian uji diagnostik dengan menggunakan desain cross-sectional. Variabel terikat penelitian ini adalah jumlah pasien yang terdeteksi positif atau negatif Diabetic Peripheral Neuropathy (DPN), sedangkan variabel bebas adalah Ankle Reflex (AR).

Sampel yang diambil adalah pasien DM tipe 2 di RSUD Dr. H. Moch. Ansari Saleh Banjarmasin pada bulan Juli hingga Agustus 2016. Kriteria inklusi penelitian ini adalah telah terdiagnosis DM tipe 2, berusia kurang dari 65 tahun dan bersedia menjadi subjek penelitian. Kriteria eksklusi penelitian ini adalah jika subjek dalam penggunaan obat-obatan kemoterapi kanker dan antiretroviral, pecandu alkohol, terdiagnosis stroke oleh dokter spesialis saraf, menderita Hernia Nukleus Pulposus (HNP), terdapat riwayat fraktur ekstremitas bawah, subjek dengan indeks massa tubuh $(I M T) \geq 25$, terdiagnosis lesi Upper Motor Neuron (UMN) oleh dokter spesialis saraf, terdiagnosis lesi saraf perifer lain oleh dokter spesialis saraf, hasil penilaian skor Diabetic Neuropathy Examination $(\mathrm{DNE}) \leq 3$, skor Diabetic Neuropathy Symptoms (DNS) $\geq 1$, dan menderita neuropati etiologi spesifik non DM berdasarkan diagnosis dokter spesialis saraf.

Instrumen yang digunakan pada penelitian ini adalah garpu tala $128 \mathrm{~Hz}$, jarum, palu refleks, lembar kuesioner DNS dan Tabel DNE. Lembar informed consent digunakan sebagai bukti persetujuan pasien sebagai subyek penelitian. Setiap pasien yang memenuhi kriteria inklusi dan eksklusi akan diberikan penjelasan tujuan, manfaat penelitian, prosedur pemeriksaan DNS, DNE dan pemeriksaan AR, kemudian pasien diminta menandatangani informed consent sebagai bukti bahwa pasien menyetujui untuk menjadi subyek penelitian. Setelah tahap persetujuan partisipan, penelitian dilanjutkan dengan pemeriksaan DNE dan DNS sebagai pemeriksaan baku emas dan pemeriksaan AR.

Analisis data dilakukan dengan tabel uji diagnostik $2 \times 2$ kemudian data diinput ke dalam aplikasi SPSS untuk mendapatkan Area Under Curve (AUC) pada kurva receiver operating characteristic (ROC). Nilai AUC menggambarkan nilai validitas. Validitas sangat baik jika AUC 90-100\%, validitas baik jika AUC 80-89,99\%, validitas cukup jika AUC 70-79,99\%, 
validitas buruk jika AUC 60-69,99\% dan validitas sangat buruk jika AUC kurang dari $60 \%{ }^{7}$

HASIL

Tabel 1. Hasil Penelitian Validitas AR sebagai Deteksi DPN pada Pasien DM Tipe 2 Tinjauan di RSUD Dr. H. Moch. Ansari Saleh Banjarmasin.

\begin{tabular}{ll}
\hline Hasil Analisis & \\
\hline Positif benar (a) & 25 \\
Positif semu (b) & 12 \\
Negatif semu (c) & 0 \\
Negatif benar (d) & 32 \\
Sensitivitas & $100 \%$ \\
Spesifisitas & $72,73 \%$ \\
1-spesifisitas & 0,277 \\
AUC & 0,88 \\
Prevalensi & $36,23 \%$ \\
Akurasi & $82,61 \%$ \\
Nilai duga positif & $67,57 \%$ \\
Nilai duga negatif & $100 \%$ \\
\hline
\end{tabular}

Hasil analisis kurva ROC untuk mengetahui AUC pemeriksaan AR dapat dilihat pada Gambar 1.

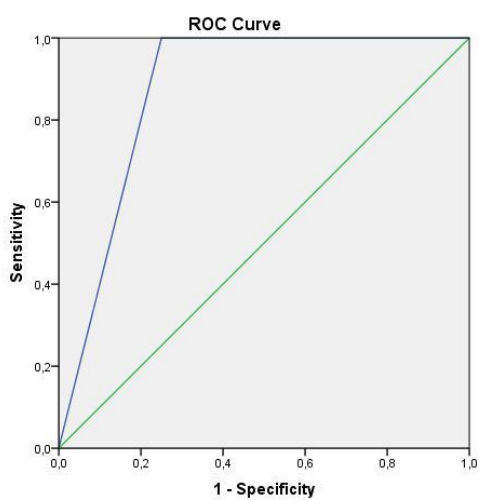

Gambar 1. Area Under Curve Validitas AR sebagai Deteksi DPN pada Pasien DM Tipe 2 di RSUD Dr. H. Moch Ansari Saleh Banjarmasin

Berdasarkan hasil pemeriksaan yang dilakukan, prevalensi penderita DPN pada penelitian ini adalah sebesar 36,23\%, yaitu 25 pasien menderita DPN dari 69 pasien menurut pemeriksaan baku emas pada penelitian ini. Hasil lain menunjukkan bahwa terdapat 32 pasien yang tidak menderita DPN menurut pemeriksaan baku emas dan AR. Terdapat 12 pasien menderita DPN menurut hasil pemeriksaan AR tetapi tidak menurut pemeriksaan baku emas.
Penghitungan menggunakan tabel $2 \times 2$ yang kemudian dianalisis menggunakan kurva ROC pada aplikasi SPSS, diperoleh hasil bahwa AR memiliki sensitivitas sebesar $100 \%$, spesifisitas $72,73 \%$, nilai duga positif $67,57 \%$, nilai duga negatif $100 \%$, akurasi 82,61\%, dan AUC 0,88.

\section{DISKUSI}

Nilai sensitivitas $100 \%$ berarti bahwa seluruh penderita DPN dengan hasil positif menurut pemeriksaan baku emas dapat terdeteksi oleh AR. Ankle reflex memiliki spesifisitas sebesar $72,3 \%$, hal ini berarti bahwa terdapat $72,73 \%$ proporsi orang tanpa DPN dengan hasil negatif menurut pemeriksaan baku emas menunjukkan hasil pemeriksaan AR positif. Nilai prediksi positif sebesar $67,57 \%$ berarti bahwa apabila hasil pemeriksaan AR didapatkan negatif maka pasien memiliki kemungkinan sebesar $67,75 \%$ untuk menderita DPN berdasarkan pemeriksaan baku emas penelitian ini. Nilai duga negatif sebesar $100 \%$ berarti bahwa jika pemeriksaan AR didapatkan positif pada pasien, maka pasien tidak memiliki kemungkinan untuk menderita DPN berdasarkan pemeriksaan baku emas penelitian ini. Nilai akurasi sebesar $82,61 \%$ berarti bahwa pemeriksaan AR mampu mendeteksi DPN dengan benar dari seluruh subjek penelitian sebesar $82,61 \%$ berdasarkan pemeriksaan baku emas. Nilai AUC 0,88 (IK 95\%: berarti bila pemeriksaan AR dilakukan pada 100 pasien maka akan memberikan kesimpulan yang benar dalam menentukan ada tidaknya DPN pada 88 pasien. Nilai AUC 0,88 tergolong nilai validitas kategori baik. Nilai AUC didapatkan dengan menghitung luas daerah trapesium pada grafik ROC, dengan nilai maksimal satu.

Tingginya nilai sensitivitas pada penelitian ini sejalan dengan hasil penelitian oleh Jayaprakash et al. (2011), ${ }^{8}$ dan Shehab et al. (2012), ${ }^{9}$ dengan nilai senstivitas berturut-turut $91,5 \%$ dan $90,7 \%$. Menurut Bowditch et al. (1996), ${ }^{10}$ hilangnya AR meningkat seiring bertambahnya usia. Rentang usia subjek penelitian yang dilakukan adalah 30-63 tahun, dengan proporsi hilangya AR sebanyak 5\% pada usia kurang dari 60 tahun dan sekitar 30\% pada usia lebih dari atau sama dengan 60 tahun. Hal ini dapat meningkatkan nilai sensitivitas dan menurunkan nilai spesifisitas AR. Hilangnya AR pada pasien DM dengan komplikasi DPN disebabkan oleh kerusakan pada serabut saraf jenis Aa yang merupakan jenis serabut saraf yang menghantarkan impuls pada lengkung reflex. Hal ini akan menyebabkan gangguan hantaran impuls yang mempersarafi lengkung refleks achilles. 
Penelitian ini memiliki keterbatasan yang dapat mempengaruhi hasil penelitian yaitu pengalaman pemeriksa. Menurut Bharati et al. (2011), ${ }^{11}$ terdapat perbedaan hasil pemeriksaan AR sebagai prosedur deteksi DPN yang dilakukan oleh mahasiswa kedokteran dan klinisi yang berpengalaman. Pemeriksaan baku emas yang digunakan pada penelitian ini berupa kuesioner dan pemeriksaan fisik, sehingga dapat dipengaruhi oleh subjektivitas pasien dan sangat bergantung pada gejala yang muncul pada pasien sehingga tidak dapat mendeteksi DPN tanpa gejala.

Menurut Perkins dan Vera (2003), ${ }^{12}$ menunjukkan bahwa pemeriksaan Nerve Conduction Study (NCS) merupakan pemeriksaan terbaik untuk mendeteksi DPN menurut American Academy of Neurology (AAN) karena dapat memberikan informasi lebih banyak untuk diagnosis DPN dan dapat mendiagnosis DPN meskipun belum ada gejala yang muncul. ${ }^{12}$

\section{SIMPULAN}

Ankle Reflex memiliki nilai validitas yang baik dan dapat digunakan sebagai prosedur deteksi DPN pada pasien DM tipe 2.

Diharapkan dapat menggunakan pemeriksaan baku emas yang lebih baik seperti NCS agar dapat mendeteksi pasien DM tipe 2 yang mengalami DPN tanpa gejala. Penelitian serupa selanjutya diharapkan dapat memuat tujuan tambahan untuk mengetahui prevalensi DPN di RSUD yang ada di Banjarmasin.

\section{DAFTAR PUSTAKA}

1. Kementerian Kesehatan RI. Infodatin Pusat Data dan Informasi Kementerian Kesehatan RI. Jakarta: Kemeterian Kesehatan RI. 2014.

2. Ametov AS, Barinov A, Dyck PJ, Hermann R, Kozlova N, Litchy WJ, et al. The Sensory Symptoms of Diabetic Polyneuropathy are Im- proved with Alpha Lipoic Acid: The Sydney rial. Diabetes care, 2003; 26 (3): 770-776.

3. Setiati S, Alwi I, Sudoyo AW. Buku Ajar Ilmu Penyakit Dalam Jilid II Edisi VI. Jakarta: Interna Publishing. 2014.

4. Sadeli HA. Nyeri Neuropati Diabetika. Dalam: Meilala L, Suryamiharja, Wirawan, Sadeli HA, Amir D. Editor. Nyeri Neuropatik. Yogyakarta: Medigama Press. 2008. P.77-90.

5. Alexandra H, Cristopher HG. Diagnosis and Treatment of Pain in Small Fiber Neuropathy. Curr Pain Headache Rep, 2011; 15 (3): 193-200.

6. Meijer JW, Bosma E, Lefrant JD. Clinical Diagnosis of Diabetic Polyneuropathy with the Diabetic Neuropathy Symptom and Diabetic Neuropathy Examination Scores. Diabetes Care, 2003; 26 (3): 697-701.

7. Sopiyudin DM. Penelitian Diagnostik Dasar-dasar Teoretis dan Aplikasi dengan Program SPSS dan Stata. Seri Evidence Based Medicine 5. Jakarta: Penerbit Salemba Medika. 2009.

8. Jayaprakash P, Anil B, Shobhit B, Pinaki D, Anantharaman R, Shanmugasundar G, et al. Validation of Beside Methods in Evaluation of Diabetic Peripheral Neuropathy. Indian J Med Res, 2011; 133 (6): 645-649.

9. Shehab DK, Al-Jarallah KF, Abraham M, Mojiminiyi OA, Al-Mohamedy H, Abdella NA. Back to Basics: Ankle Reflex in the Evaluation of Peripheral Neuropathy in Type 2 Diabetes Mellitus. QJM, 2012; 105 (4): 315-320.

10. Bowditch MG, Sanderson P, Livesey JP. The Significance of an Absent Ankle Reflex. J Bone Joint Surg, 1996; 78 (2): 276-279.

11. Bharati T, Saima A, Ashish J, Vikas K. The Diagnostic Sensitivity, Specificity and Reproducibility of the Clinical Physical Examination Signs in Patients of Diabetes Mellitus for Making Diagnosis of Peripheral Neuropathy. J Endocrinol Metab, 2011; 1 (1): 21-26.

12. Perkins BA, Vera B. Diabetic Neuropathy: A Review Emphasizing Diagnostic Methods. Clin Neurophysiol, 2003; 114 (7): 1167-1175. 